\title{
Hepatitis Prevalence of Epidemic Magnitude among Sanitary Workers in Pakistan
}

\author{
Shakeel Waqqar ${ }^{*}$,Salman Aziz², Godfrey Paul William ${ }^{3}$, Farheen Ansari ${ }^{4}$ \\ Saima Bano ${ }^{5}$ \\ 1,4 Center of Research in Molecular Medicine, Department of Microbiology, University of Lahore, Lahore. \\ 2 Head of periodontology department, University medical \& dental college, University of Faisalabad. \\ 3 Fatima Memorial Medical College Lahore, 5 Punjab University, Lahore
}

\begin{abstract}
Hepatitis is among the world's most prevalent and life threatening diseases. High risk populations like sanitary workers dealing with all sorts of infective materials are easy targets for transmission of this killer disease. The primary objective of our study is to determine the burden of hepatitis $B$ and $C$ among people belonging to this occupation. The secondary objective is to compare the efficacy of ELISA with ICT for screening of both the maladies. 107 subjects who gave informed consent were included in this study. Blood samples were drawn and screening performed with both ELISA and ICT. For HCV, 26 subjects were found to be sero-positive with ICT while 39 were positive with ELISA. For HBV, 20 subjects were found sero-positive with ICT and 36 with ELISA. Our study found that there is a high burden of HBV and HCV among sanitary workers and therefore, there is a great need to devise preventive regimens for protection of this high risk group against viral hepatitis.

Objectives: To evaluate the burden of Hepatitis B \& C among Sanitary Workers in Pakistan, To compare the sensitivity of ICT and ELISA for screening of $H B V$ and $H C V$
\end{abstract}

\section{Introduction}

Hepatitis is among the world's most prevalent and life threatening diseases. There are many causes of the hepatitis but viruses are the leading cause of hepatitis. Viral hepatitis is a growing concern of public health especially among the developing countries. Currently, six types of the viruses are known as causative agents of viral hepatitis. These are types A, B, C, D, E and G. Among these Hepatitis B \& hepatitis C are well known for the chronic infections and causing considerable morbidity and mortality.

Prevalence of Hepatitis B in Pakistan is between 2.3 to $2.5 \%$, whereas Hepatitis C is more prevalent among the public ranging from 2.6 to $5.3 \%$ [1]. Globally $2.2 \%$ population is infected with the Hepatitis C, while Pakistan stands $2^{\text {nd }}$ in the list of world's most prevalent nations with hepatitis C [2].

In Pakistan there are 7 to 9 million infected patients who are in the carrier state which represent 3 to 5 $\%$ portion of the total population [3]. Studies show that men are more at risk than women; teenagers present even greater risk of infection as compared with the older population and children. Males are 2.14 percent more likely to be infected with HBV than females [4]. A significant difference exists between those who are below thirty and above thirty, people below 30 years are 12 percent more infected than the population above this age (4). There are a number of occupational issues related to hepatitis infection associated with different trades. People associated with garbage collection, waste management, and hospital sanitary workers are considered as very high risk groups especially in Pakistan, where occupational safety is mostly compromised specially in low income trades. These people are often uneducated, have low income, under resourced for the access to proper medication and treatment. Clinically, they often present cuts, open skin and occupational injuries with sharp instruments or needles, which could be predicted as the major source of infection [5]. High association of the viral hepatitis among the sanitary workers is predictable if one has a clear view of the working conditions for this socio-economically deprived population in Pakistan.

Prevalence of hepatitis $\mathrm{C}$ in Pakistani population varies in selective target groups including health professionals, drug abusers, and garbage scavengers. Studies show hepatitis prevalence of up to $40 \%$ in some groups $[6,15]$. About 1 million deaths are reported every year due to hepatitis B \& C [7]. Chronic liver disease 
like hepatitis B \& C are a greater challenge. Together hepatitis B and hepatitis $\mathrm{C}$ have been implicated as the leading cause of liver cancer (Hepatocellular Carcinoma) occurring in $78 \%$ of the infected cases around the world. Transmission of hepatitis B is associated with body fluids, semen, and needle stick injury and from mother to infant during early childhood $[4,6,7]$. Hepatitis $\mathrm{C}$ is considered as a blood born pathogen and transmitted through blood transfusion, needle stick injury, open skin contact with blood and sexual contact. Treatment of the hepatitis B is believed to reduce risk of liver cancer but only 20 to $30 \%$ of the patients are believed to get real benefits of the current available treatment. The efficiency further reduces to $10 \%$ with coinfection of HIV and HCV. HCV is considered as the treatable condition but for most it comes at a very high cost and majority of the people cannot afford it in developing countries [7, 14]. Therefore, there is a great need to identify high risk groups and intervene with preventive strategies to reduce the overall burden of this killer disease. The aim of this study is therefore, to determine the burden of HBV and HCV among the high risk population of sanitary workers in Pakistan.

\section{Material And Methods}

All the participants were identified as permanent full time sanitary workers, mainly associated with opening of drains, large sewage ducts and sewage piping's. Purpose of the study was explained to all of the participants. All of the candidates were offered a free medical check-up and free blood tests for hepatitis B and hepatitis C. After informed consent, blood samples were drawn, serum was separated and kept at minus $20 \mathrm{C}^{0}$ until analysed. All of the samples were tested for anti HCV and HBsAg by immuno-chromatographic method followed by ELISA and PCR. All of the sero-positive samples were processed for qualitative real time polymerase chain reaction (RT-PCR). All of the candidates were informed about their test results, those with positive ELISA and PCR were referred to a Hepatologist for treatment. Obtained data was analysed by SPSS 20.

\section{Results}

A total of 107 candidates participated in this study were working in the sanitation occupation for at least 5 years or greater. Age range of the participants was between 20 and 48 years. Their average monthly income was $70 \pm 8$ dollars month.

Twenty six (26) were positive by immuno-chromatography (ICT) for hepatitis $\mathrm{C}$ and 81 were found negative with percentages of $24.3 \%$ and $75.7 \%$ respectively. Sero positivity for HCV was considerably greater with enzyme linked immuno-sorbent assay (ELISA), 39 samples (36.4\%) were positive and 68(63.6) negative for HCV by ELISA. For HBsAg ICT showed positivity in 20 samples (18.7\%) and 36 candidates (33.6\%) were sero positive with ELISA. Therefore, ELISA showed less negativity $66.4 \%(\mathrm{n}=71)$ as compared to samples run with ICT $81.3 \%(n=87)$. Therefore, ELISA has more sensitivity for detection of HBsAg.

All the ELISA positive samples were run for RT-PCR according for sero positivity. Thirty nine (39) samples were processed for HCV RT-PCR and 36 for HBV RT-PCR. HCV ribonucleic acid (RNA) was found in 99\% samples which were sero positive for HCV. Deoxyribonucleic acid (DNA) of HBV was positive in $94 \%$ of the HBsAg sero positive samples.

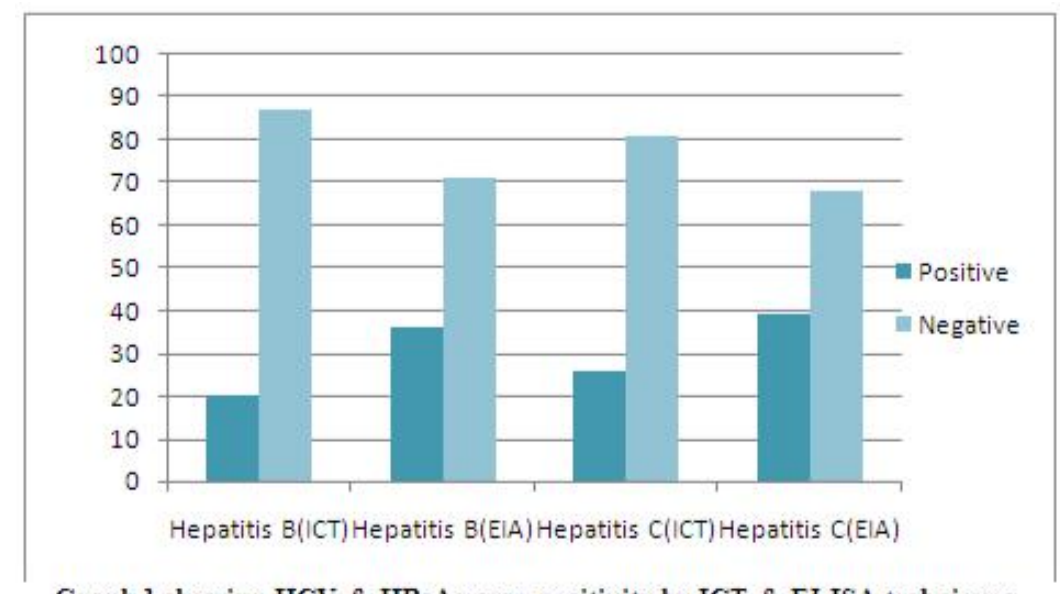

Graph 1 showing HCV \& HBsAg sero-positivity by ICT \& ELISA techniques. 


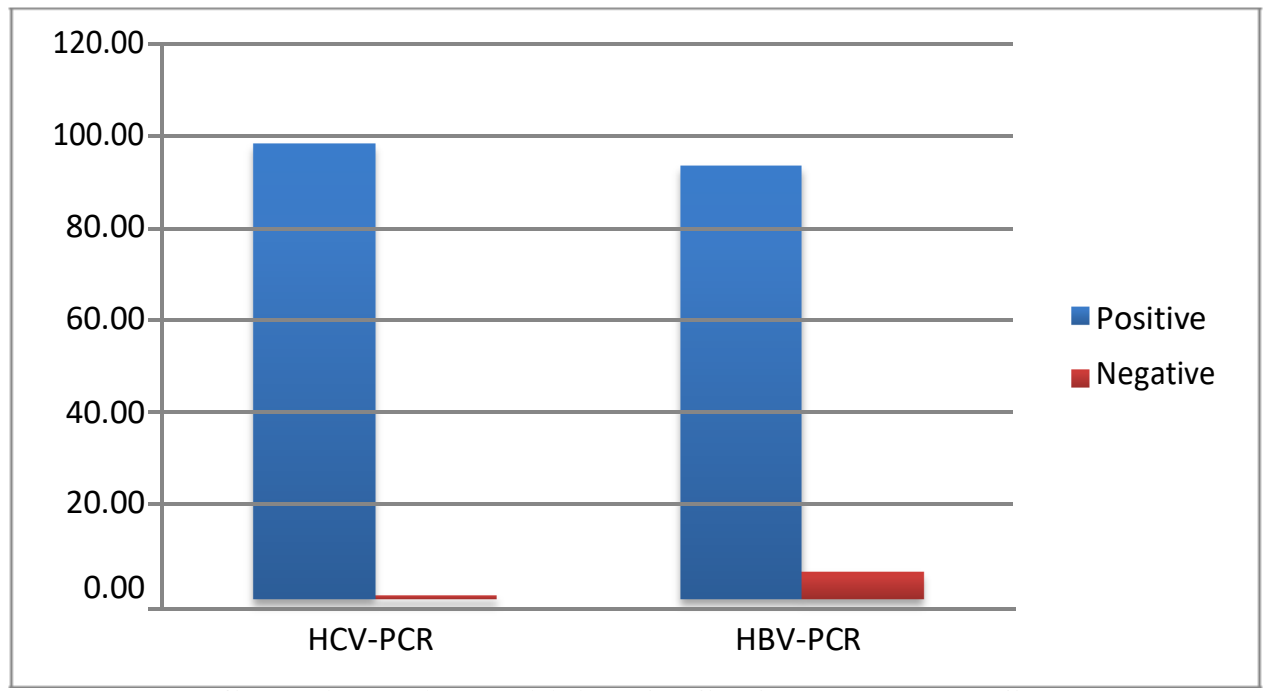

Graph 2 showing positivity of HCV \& HBV by RT-PCR

\section{Conclusion}

Present study found that in Pakistan, sanitary workers are exposed to the hazardous and fatal occupational injury putting them at risk of great burden of viral hepatitis because of the following factors:Illiteracy, Poverty, Limited access to health care system, lack of immunization, Poor standards of waste disposal, Ignorant attitude by waste management departments and non-availability of health coverage.

The lethargy or the inability of the government's capacity to establish W.H.O approved standards of operations and policies to protect public, both the service providers and the resident population is therefore, evident.

Viral Hepatitis is a rapidly growing challenge, which is becoming a national epidemic; highest priority has to be given towards devising effective preventive strategies.

\section{Discussion}

Hepatitis B \& C viruses are well known for the high rates of transmission and infection. Both the viruses are responsible for morbidity and mortality on global scale. Their chronic nature of infection leads to long term illness and major financial burden. Different reports show greater variation of hepatitis B \& C prevalence in different areas of the country; these variations may be due to cultural differences. A study by Maqbool et al in 2011 showed that the people who were recruited as sanitary workers were tested for hepatitis viruses and even at that stage they showed increased incidence of viral hepatitis than the people recruited for other trades. He concluded that prevalence of hepatitis B \& C among sanitary workers at selection stage was $5.64 \%$ compared with other trades as $2.25 \%$ [8]. However, there was no data available regarding the prevalence among current sanitary workers. Our study reports the prevalence of HBV to be $33.6 \%$ with ELISA while HCV was present in $36.4 \%$ of the population studied.

Sanitary workers in Pakistan are handling bare handed the garbage, hospital waste, sewage drainage and highly pathogenic materials of the medical laboratories and hospitals. Most of them are never provided with the safety equipment nor are they taught for safety and health concerns. Studies showed that workers of waste management and sanitation are at greater risk of acquiring hepatitis infection as they are in direct and unprotected contact of deadly pathogens $[9,10]$. Studies also showed that increasing age increases the risk of viral hepatitis [11].

Our study on the other hand, showed that young people were at higher risk of exposure; one probable reason could be that young people are more active in work and are forced to complete tasks swiftly. Or there may be familial transmission as mostly sanitation is a family occupation in Pakistan and a group of specified people are involved in this trade. Present study shows that more than $95 \%$ of the people associated with this trade never went to school. Past studies showed that incidence is significantly associated with educational status [12].

Our study revealed that socio-economic status of the participants was low. Studies by Akbar et al. and Faridullah et al showed that transmission of the hepatitis is greater among the families with lower socioeconomic status [13,14]. A study by Rauf et al from Karachi showed that prevalence of hepatitis B \& C among the garbage scavengers was $8.5 \%$ and $18.5 \%$ respectively [15]. Present study also shows that people associated 
with the trade of sewage in Pakistan, present the highest prevalence of hepatitis B \& C among the previously studied high risk groups.

\section{Recommendations And Future Guide Lines}

It is our recommendation that people who are not infected should be vaccinated to prevent the diseases and who are diseased should be treated properly. Viral hepatitis is an alarming health issue and requires considerable efforts to lower the disease burden in these groups and general population thereby increasing the cost of disease and aftermath management in public sector hospitals.

\section{Acknowledgement}

We acknowledge the strong support by Prof. Dr M.H Qazi, Director Center of Research in molecular medicine, University of Lahore, Pakistan.

*We are thankful to the IOSR for accepting the changes.

\section{References}

[1]. Altaf Bosan, Irtaza Ahmad, Rehan Hafiz, Huma Qureshi, Khalif Mohamud Bile JPMA, A review of hepatitis viral infections in Pakistan

[2]. Alter MJ. Epidemiology of hepatitis C virus infection. World J Gastroenterol. 2007; 13:2436-2441.

[3]. Khan $\mathrm{F}$ et al, Hepatitis B virus infection among different sex and age groups in Pakistani Punjab. Virol J. 2011 May 13;8:225. doi: 10.1186/1743-422X-8-225.

[4]. Rachiotis G, Papagiannis D, Markas D, Thanasias E, Dounias G, Hadjichristodoulou C. Hepatitis B virus infection and waste collection: prevalence, risk factors, and infection pathway. Am J Ind Med 2012; 55: 650-5

[5]. Ali M et al, Hepatitis B virus in Pakistan: a systematic review of prevalence, risk factors, awareness status and genotypes. Virol J. 2011 Mar 6;8:102. doi: 10.1186/1743-422X-8-102.

[6]. Abbas Z, Jeswani NL, Kakepoto GN, Islam M, Mehdi K, Jafri W. Prevalence and mode of spread of hepatitis B and C in rural Sindh, Pakistan. Trop Gastroenterol. 2008; 29: 210-6.

[7]. www.who.int/csr/disease/hepatitis/world_hepatitis day question... en

[8]. Maqbool Alam, Frequency of Hepatitis B \& C in adults seeking recruitment as sanitary workers, Pakistan Journal of Pathology 2011; 22(2): 80-81, Combined Military Hospital, Attock, Pakistan.

[9]. Brautbar N, Navizadeh N. Sewer workers: Occupational risk for hepatitis C-report of two cases and review of literature. Arch Environ Health 1999; 54: 328-330.

[10]. Murrill CS, Weeks H, Castrucci BC, et al. Age-specific seroprevalence of HIV, hepatitis B virus, and hepatitis C virus infection among injection drug users admitted to drug treatment in 6 US cities. Am J Public Health 2002; 92: 385-387.

[11]. Alter MJ. Hepatitis C virus infection in the United States. J Hepatol 1999; 31: 88-91

[12]. Arvanitidou M, Constantinidis TC, Doutsos J, Mandraveli K, Katsou yannopoulos V. Occupational hepatitis B virus infection in sewage workers. Med Lav 1998; 89: 437-444.

[13]. Akbar N, Basuki B, Mulyanto, Garabrant DH, Sulaiman A, Noer HM. Ethnicity, socioeconomic status, transfusions and risk of hepatitis B and hepatitis C infection. J Gastroenterol Hepatol 1997 Nov; 12: 752-757.

[14]. Faridulla, Salih M, Malik IA, Hussain I. Increasing prevalence of chronic hepatitis and associated risk factors. Pak J Med Res 2002; 41: 46-50.

[15]. Rauf MU, Saleem MD, Anwar MO, Ahmad G, Aziz S, Memon MA, HIV, hepatitis B and hepatitis C in garbage scavengers of Karachi, J Pak Med Assoc 2013 Jun: 63 (6) : 798-802 